\title{
REFLEXÕES SOBRE A CONCORDÂNCIA DE NÚMERO EM SINTAGMAS NOMINAIS (SNs) COMPLEXOS NO PORTUGUÊS DE ANGOLA (PA)
}

\author{
REFLEXIONES SOBRE LA CONCORDANCIA DE NÚMEROS EN SINTAGMAS \\ NOMINALES COMPLEJOS (SNS) EN ANGOLA PORTUGUESA (PA)
}

\author{
REFLEXIONS ON NUMBER CONCORDANCE IN COMPLEX NOMINAL SYNTAGMS \\ (SNS) IN ANGOLA PORTUGUESE (PA)
}

\author{
Hermenegildo Kâmbua da Costa PINTO ${ }^{1}$ \\ Jeremias Dandula PESSELA ${ }^{2}$
}

RESUMO: Neste trabalho, procuramos descrever o fenômeno da concordância de número em sintagmas nominais (SNs) complexos que desempenham a função sintática de objeto direto da frase, em estudantes angolanos, bilíngues com L1 português e L2 bantu, ou viceversa. Pretendemos avaliar também o tratamento dado ao fenômeno da concordância no SN, do ponto de vista do ensino e aprendizagem. O estudo baseia-se nas teorias de variação linguística e de ensino aprendizagem de línguas, por oferecerem explicações para a ocorrência de desvios na aquisição de línguas não-maternas. O tipo de pesquisa é misto. Os dados analisados indicam que os estudantes angolanos utilizam um mecanismo de concordância misto em SNs que têm a sua esquerda palavras nucleares de categorias funcionais como artigos definido, numerais e quantificadores. Nestes casos, o plural é marcado nesses elementos e não no nome. Ademais, o fato de nos documentos normativos do processo de ensino e aprendizagem do Português não considerarem aspectos do contato do Português com as línguas bantu faladas em Angola dificulta a apropriação correta dos mecanismos de concordância.

PALAVRAS-CHAVE: Número gramatical. Concordância nominal no PA. Ensino do português.

RESUMEN: En este trabajo se pretende describir el fenómeno de la concordancia numérica en frases nominales complejas (SNs) que tienen la función sintáctica de objeto directo de la oración, en estudiantes angoleños, bilingües con L1 portugués y L2 bantú, o viceversa. También pretendemos evaluar el tratamiento dado al fenómeno de la concordancia en el SN, desde el punto de vista de la enseñanza y el aprendizaje. El estudio se basa en las teorías de la variación lingüística y de la enseñanza del aprendizaje de lenguas, ya que ofrecen explicaciones sobre la aparición de desviaciones en la adquisición de lenguas no nativas. El tipo de investigación es mixto. Los datos analizados indican que los alumnos angoleños

1 Escola Superior Pedagógica do Bié (ESP-Bié), Cuíto - Angola. Docente de Língua Portuguesa no Departamento de Ciências da Educação. Doutorado em Linguística (UEVORA) - Portugal. ORCID: https://orcid.org/0000-0002-9936-4482.E-mail: hermenetina@gmail.com

${ }^{2}$ Escola Superior Pedagógica do Bié (ESP-Bié), Cuíto - Angola. Docente de Língua Inglesa e Portuguesa no Departamento de Ciências da Educação. Mestrado em Linguística Geral e Portuguesa (UP-PORTUGAL) Portugal e Doutorando em Ciências da Linguagem (UP-PORTUGAL) - Portugal. ORCID: https://orcid.org/0000-0002-0027-0946.E-mail: jeremia spessela@yahoo.com.br 
utilizan un mecanismo de concordancia mixto en los $S N$ que tienen a su izquierda palabras centrales de categorías funcionales como articulos definidos, numerales y cuantificadores. En estos casos, el plural se marca en estos elementos y no en el sustantivo. Además, el hecho de que los documentos normativos sobre el proceso de enseñanza y aprendizaje del portugués no consideren aspectos del contacto del portugués con las lenguas bantúes habladas en Angola dificulta la correcta apropiación de los mecanismos de acuerdo.

PALABRAS CLAVE: Número gramatical. Acuerdo nominal en PA. Enseñanza del portugués.

ABSTRACT: This paper aims to describe the phenomenon of number agreement in complex DPs that perform the syntactic function of the direct object of the sentence, in Angolan students, bilingual with Portuguese L1 and Bantu L2, or vice versa. We also intend to evaluate the treatment given to the phenomenon of concordance in the DPs, from the point of view of teaching and learning. The study is based on linguistic variation and language learning teaching theories, as they offer explanations for the occurrence of deviations in the acquisition of non-native languages. The search type is mixed. The published data indicate that Angolan students use a mixed agreement mechanism in DPs that have to their left core words of categories defined as definite articles, numerals and quantifiers. In these cases, the plural is marked as elements and not in the name. Furthermore, the fact that in the normative documents of the process of teaching and learning of Portuguese does not consider aspects of the contact of Portuguese with the Bantu languages spoken in Angola, difficulty in correctly appropriating agreement mechanisms.

KEYWORDS: Grammatical number. Nominal agreement in AP. Teaching Portuguese.

\section{Introdução}

No processo de ensino e aprendizagem do Português em Angola, um dos pontos nefrálgicos é o ensino da concordância de número no Sintagma Nominal (SN). Apesar de o Português ser a língua oficial do país (cf. art. 19 da $\mathrm{CR}^{3}$ ) estão presentes outras línguas, com destaque para as línguas de origem bantu. As dificuldades em estabelecer a concordância de número no SN exacerbam-se quando este é constituído por elementos que são núcleos de categorias funcionais, tal como determinantes, numerais e quantificadores. Partindo do princípio, segundo o qual as línguas bantu são línguas sem artigos, e muitos falantes são expostos a inputs pouco robustos da norma do Português Europeu (PE) (ZAU, 2011), as dificuldades em manter todos os mecanismos de concordância em SNs constituídos por determinantes, numerais e quantificadores tendem a ser mais difíceis, o que, a partida, levanta um grande desafio, quer para os alunos quer para os professores. No PA, predomina uma estratégia variável na marcação do número gramatical. Vários autores como Inverno (2009),

${ }^{3}$ Constituição da república. 
Adriano (2014), Marques (1983) consideram que na marcação do plural nos elementos do SN, em falantes do PA, é recorrente a não marcação do plural no nome $(\mathrm{N})$ por influência de línguas de substrato bantu, pelo que, segundo Pessela (2020, p. 39):

A ausência da marcação do plural no $\mathrm{N}$ justifica-se pelo contacto do português com as línguas bantu faladas em Angola. Tudo indica que os falantes do PA, ao adquirirem o português, interpretam os nomes como invariáveis, e consideram os determinantes (artigos) como equivalen tes dos prefixos nominais das línguas bantu.

Neste trabalho, procuramos descrever o fenômeno da concordância de número em SNs complexos constituídos por: (i)Art. def. $[+$ pl $]+\mathrm{N}$ [- pl]: (Artigo Definido [+ plural $]+$ Nome [- plural]); (ii)Art. def. [- pl] + Poss. [+ pl] + N [- pl]: (Artigo definido [- plural] + Possessivo [+ plural] + Nome [- plural]); (iii) Num. + N [- pl]: Numeral + Nome [- plural]; (iv) Quant.+ N [- pl]: Quantificador + Nome [- pl]. Assim, objetivamos avaliar as tendências mais comuns de marcação da concordância de número nos SNs complexos, que desempenham a função sintática de objeto direto da frase, em estudantes angolanos, bilíngues com L1 português e L2 bantu, ou vice-versa. Pretendemos avaliar também o tratamento dado ao fenômeno da concordância variável no SN no PA do ponto de vista do ensino e aprendizagem. Para o efeito, analisamos os principais documentos orientadores do referido processo, nomeadamente os programas e os manuais de Português da $6^{\mathrm{a}}$ e $10^{\mathrm{a}}$ classes, bem como do $1^{\mathrm{o}}$ e $2^{\mathrm{o}}$ ano do ensino superior de formação de professores. O trabalho está constituído por uma introdução, revisão bibliográfica, apresentação dos dados e sua discussão, considerações finais e referências bibliográficas.

\section{Revisão bibliográfica}

A concordância de número no $\mathrm{SN}$ é a relação que se estabelece entre o Nome e os seus especificadores e modificadores (determinantes, quantificadores e adjetivos) que constituem o $\mathrm{SN}$, é feita em número (plural ou singular). O número gramatical é considerado um dos universais linguísticos na lista de Greenberg (1963). Todas as línguas do mundo marcam o número. Contudo, as línguas possuem mecanismos diferentes da marcação do número gramatical, podendo ser pelo uso de desinências, prefixos nominais, entre outros, conforme os exemplos seguintes.

a. Os gatos brancos são lindos. (PE)

b. Os aluno são inteligente. (PA) 
c. The books are green. (ING)
d. Olongato vykusuka vyafina ${ }^{4}$. (umbundo)

Apresentados os exemplos anteriores notamos que há uma provável relação no mecanismo de concordância de número no SN das frases (b) e (d), pois há autores que defendem que os falantes do PA fazem uma transferência de substrato gramatical das línguas bantu. A concordância nessas línguas é feita através da junção ao Nome de prefixos que são comutados para os outros constituintes do SN. Em alguns casos, há uma forma para substantivos e adjetivos, e uma segunda forma para possessivos e demonstrativos, geralmente marcadores de objetos e outras categorias menores (KATAMBA, 2003, p. 103). No entanto, diferente do PE, que tem um mecanismo de concordância múltiplo (cf. ex. a) o no PA nota-se uma tendência em marcar apenas para o plural o elemento mais à esquerda do $\mathrm{SN}$, normalmente um artigo, um numeral ou outro elemento de uma categoria da classe dos determinantes e quantificadores, sendo defendido por vários autores como sendo produto do contato entre o português e as línguas locais de origem bantu.

\title{
Apresentação e discussão dos dados
}

Os dados da presente pesquisa foram obtidos através da aplicação de uma entrevista de natureza semiaberta e da análise documental dos programas e manuais de Português da $6^{\mathrm{a}}, 10^{\mathrm{a}}$ e $11^{\mathrm{a}}$ classes e do $1^{\circ}$ e $2^{\circ}$ ano do ensino universitário. A escolha da entrevista foi devido ao que defende Gonçalvez (2013). Segundo a autora:

\begin{abstract}
Os estudos atualmente disponíveis sobre o PA apresentam breves listas de alguns traços mais salientes da sua gramática ou se referem a uma subvariedade particular. Por outro lado, nos casos em que são apresentadas descrições do PA de alcance mais geral, a base empírica é constituída por textos literários, que dificilmente podem ser considerados representativos da gramática da língua oral, tal como foi fixada pela comunidade de falantes desta língua (GONÇALVEZ, 2013, p. 162).
\end{abstract}

Participaram da entrevista noventa e cinco (95) informantes, sendo quarenta e oito do ensino primário, trinta e dois do ensino secundário, e quinze do ensino superior. Todos os informantes são residentes do município do Cuito, província do Bié. Os informantes têm idade variável entre os dez e doze anos para os do ensino primário, treze a dezesseis anos para os do ensino secundário e dezessete a trinta e seis anos para os do ensino superior. Todos os

${ }^{4}$ Os gatos brancos são lindos. 
informantes são bilingues, e têm o Português como L1 para uma minoria e L2 para a maioria. Para melhor compreensão, os dados são detalhados na tabela (1) que se segue.

Figura 1 - Tabela de dados dos informantes

\begin{tabular}{|c|c|c|c|}
\hline Variáveis & Descrição & $\begin{array}{c}\text { Frequência } \\
\text { relativa }\end{array}$ & $\%$ \\
\hline \multirow{4}{*}{ Idade } & $10-12$ anos & 48 & $50,5 \%$ \\
\hline & $13-16$ anos & 31 & $32,6 \%$ \\
\hline & $17-35$ anos & 16 & $16,8 \%$ \\
\hline & total & 95 & $100 \%$ \\
\hline \multirow{8}{*}{ Língua materna } & luimbi & 1 & $1,0 \%$ \\
\hline & kikongo & 1 & $1,0 \%$ \\
\hline & tchókwe & 2 & $2,0 \%$ \\
\hline & luvale & 1 & $1,0 \%$ \\
\hline & nganguela & 4 & $4,2 \%$ \\
\hline & português & 49 & $51,5 \%$ \\
\hline & umbundu & 37 & $38,9 \%$ \\
\hline & total & 95 & $100 \%$ \\
\hline \multirow{3}{*}{ Zona de residência } & urbana & 23 & $24,2 \%$ \\
\hline & periurbana & 72 & $75,7 \%$ \\
\hline & Total & 95 & $100 \%$ \\
\hline
\end{tabular}

Fonte: Pessela (2020, p. 63)

Para a quantificação e a organização dos dados utilizámos o software SPSSl. O programa possibilitou-nos fazer os cálculos e o cruzamento das variáveis linguísticas (função sintática, estrutura do SN, presenças da marca de plural e ausência da marca do plural) com as variáveis sociais idade, língua materna, nível de escolaridade e zona de residência dos informantes. Com o objetivo de compreender se a função de objeto direto tem alguma influência na falta de marcação da concordância de número nos $\mathrm{SNs}$, recolhemos vários exemplos produzidos nas entrevistas. Encontramos quatro tipos de SNs com problemas de marcação de plural nesta função sintática:
a) Art. def. $[+\mathrm{pl}]+\mathrm{N}[-\mathrm{pl}]$
b) Art. def. [- pl] + Poss. [+ pl] + N [- pl]
c) Num. + N [- pl]
d) Quant.+N [- pl] 
Em (2) ilustramos algumas das ocorrências encontradas.

(2) (exemplos extraídos de PESSELA, 2021, p. 54)

1. a)... lavar os prato.

2. b) Depois... terminar os meus estudo.

3. c) Tenho nove disciplina.

4. d) Tenho muitos livro.

Os resultados totais estão condensados na tabela seguinte:

Figura 2 - Tabela de resultados dos SNs com a concordância de número divergente da norma do PE com a função sintática de objeto direto

\begin{tabular}{|c|c|c|c|c|c|c|c|c|c|c|c|c|c|}
\hline Função Sintática & \multicolumn{11}{|c|}{ Variáveis sociais } & & \\
\hline \multirow[t]{2}{*}{ Objeto direito } & \multicolumn{3}{|c|}{ Idade } & \multicolumn{6}{|c|}{ Língua materna } & \multicolumn{2}{|c|}{$\begin{array}{l}\text { Zona de } \\
\text { residência }\end{array}$} & \multicolumn{2}{|l|}{ Total } \\
\hline & $\begin{array}{l}\text { I } \\
\text { ! }\end{array}$ & $\begin{array}{l}0 \\
1 \\
m\end{array}$ & $\begin{array}{l}n \\
1 \\
=\end{array}$ & $\begin{array}{l}\text { 를 } \\
\text { 音 } \\
\text { 晋 }\end{array}$ & 泾 & 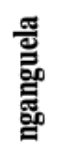 & 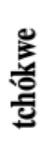 & 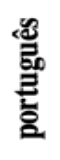 & $\begin{array}{l}\text { 当 } \\
\text { 晋 } \\
\text { 严 }\end{array}$ & $\begin{array}{l}\text { 芯 } \\
\text { 总 }\end{array}$ & 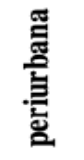 & हึँ & $b^{2}$ \\
\hline $\begin{array}{l}\text { Art. defin. }[+ \text { pl }]+N \\
{[- \text { pl }]}\end{array}$ & 9 & 8 & 1 & 0 & 0 & 0 & 0 & 11 & 7 & 4 & 14 & 18 & $10,5 \%$ \\
\hline $\begin{array}{l}\text { Art. def.[+ pl] + } \\
\text { Poss. [+ pl]+ N[- pl] }\end{array}$ & 0 & 1 & 1 & 0 & 0 & 0 & 0 & 1 & 1 & 1 & 1 & 2 & $1,0 \%$ \\
\hline Num. + N [- pl] & 109 & 24 & 12 & 0 & 0 & 0 & 3 & 88 & 57 & 17 & 128 & 145 & $85 \%$ \\
\hline Quant.+ N [- pl] & 0 & 3 & 2 & 0 & 0 & 0 & 0 & 4 & 1 & 2 & 3 & 5 & $3,0 \%$ \\
\hline Total & & & & & & & & & & & & 170 & 100 \\
\hline
\end{tabular}

Fonte: Pessela (2020, p. 84)

Como a tabela 2 mostra, os SNs com a concordância de número divergente da norma do PE com a função sintática de objeto direto tiveram uma ocorrência total de $170 \mathrm{SNs}$, em 287, correspondendo a 59,2\%. Quanto à sua estrutura destacamos: 


\section{a) Artigo definido $[+\mathrm{pl}]+$ Nome $[-\mathrm{pl}]$}

Nos SNs constituídos por Artigo definido [+ pl] + Nome [- pl], com a funcão sintática de objeto direto, conforme o exemplo em (2a), encontramos 18 ocorrências (10,5\%) de um total de 170 .

Relacionando a ocorrência com a variável sociolinguística idade, encontramos $50 \%$ para os informantes com idade entre dez e doze anos, $44,4 \%$ para os informantes com idade entre treze e dezesseis anos e 5,5\% para os informantes com idade entre dezessete e trinta e cinco anos.

Quanto à variável língua materna, encontramos 38,8\% para os informantes que têm o umbundu como língua materna e $61,1 \%$ para os informantes que têm o português como língua materna.

Relativamente à variável zona de residência, encontramos $22 \%$ para os informantes residentes na zona urbana e $77,7 \%$ para os informantes residentes na zona periurbana.

\section{b) Artigo definido $[+\mathrm{pl}]+$ Possessivo $[+\mathrm{pl}]+\mathbf{N}[-\mathrm{pl}]$}

Relativamente aos SNs constituídos por Artigo definido $[+\mathrm{pl}]+$ Possessivo $[+\mathrm{pl}]+$ Nome [- pl], com a função sintática de objeto direto, conforme o exemplo em (2b), encontramos 2 ocorrências (1,2\%), de um total de 170 (100\%).

Relacionando a ocorrência com a variável sociolinguística idade, encontramos $0 \%$ para os informantes com idade entre dez e doze anos, 50\% para os informantes com idade entre treze e dezesseis anos e 50\% para informantes com idade entre dezessete e trinta e cinco anos.

Quanto à variável língua materna, encontramos 50,0 \% para os informantes que têm o umbundu como língua materna e 50,0 \% para os informantes que têm o português como língua materna.

Relativamente à variável zona de residência, encontramos 50,0\%, para os informantes residentes na zona urbana e 50,0\% para os informantes residentes na zona periurbana.

\section{c) Numeral + Nome [- pl]}

Nos SNs constituídos por Numeral + Nome [- pl], com a função sintática de objeto direto, conforme o exemplo em (2c), encontramos 145 ocorrências (85\%), de um total de 170.

Relacionando a ocorrência com a variável sociolinguística idade, temos 75,0\% para os informantes com idade entre dez e doze anos, $16 \%$ para os informantes com idade entre treze e dezesseis anos e $8,2 \%$ para os informantes com idade entre dezessete e trinta e cinco anos. 
Quanto à variável língua materna, encontramos 2,0\% para os informantes que têm o tchókwe como língua materna, 36,3\% para os informantes que têm o umbundu como língua materna e $60,6 \%$ para os informantes que têm o português como língua materna.

Relativamente à variável zona de residência, temos $11,7 \%$ para os informantes residentes na zona urbana e $88,2 \%$ para os informantes residentes na zona periurbana.

\section{d) Quantificador + Nome [- pl]}

Nos SNs constituídos por Quantificador + Nome [- pl], com a função sintática de objeto direto, conforme o exemplo em (2d), encontramos 5 ocorrências $(3,0 \%)$ de um total de $165(100 \%)$.

Relacionando a ocorrência com a variável sociolinguística idade, encontramos $0,0 \%$ para os informantes com idade entre dez e doze anos, $60 \%$ para os informantes com idade entre treze e dezesseis anos e 40, \% para informantes com idade entre dezessete e trinta e cinco anos.

Quanto à variável língua materna, encontramos 20,0\% para os informantes que têm o umbundu como língua materna e $80,0 \%$ para os informantes que têm o português como língua materna.

Quanto à variável zona de residência, encontramos $40 \%$ para os informantes residentes na zona urbana e $60 \%$ para os informantes residentes na zona periurbana.

Percebemos que os falantes mais novos (10-13 anos) e (12-16 anos) que têm o português L1 e que provêm da zona periurbana têm alguma tendência para marcarem o plural só no artigo. Se houver um numeral, sendo este elemento muito claro quanto ao significado de pluralidade, então é neste contexto que há um número significativo de "desvios" e maior tendência para não marcar o nome com o plural. Com os possessivos, há tendência para marcar o plural quer no artigo quer no possessivo, não parecendo justificar-se a tendência apresentada por Costa e Figueiredo Silva (2010) para o PB.

De forma geral, da análise feita nos programas constatamos que estes são analíticos, não oferecendo detalhes sobre o tratamento a dar a concordância. O Programa de língua Portuguesa da $6^{\text {a }}$ Classe, por exemplo, apresenta uma seção dos objetivos gerais do ensino primário, de entre os quais destaca-se: "Utilizar corretamente a Língua Portuguesa para comunicar de forma adequada e estruturar o pensamento lógico, através do cumprimento das regras gramaticais ou funcionamento da língua" (SILVA, 2010, p. 8). No mesmo âmbito da $6^{\mathrm{a}}$ Classe, especificamente faz-se menção aos seguintes objetivos: "Aplicar corretamente os 
conteúdos gramaticais adequados à classe e ao nível, bem como os conhecimentos adquiridos nas classes anteriores" (SILVA, 2010,p. 8).

Não havendo no programa qualquer referência sobre o que é correto gramaticalmente, espera-se que tal vertente seja abordada nos manuais concebidos para o ensino da língua portuguesa. Todavia, neles não há igualmente um grande desenvolvimento deste aspecto. $\mathrm{O}$ manual da $10^{\mathrm{a}}$ classe trata o assunto das classes gramaticais apenas de leve, não fazendo referência à concordância de número, estando este aspecto apenas implícito nos exemplos apresentados, cuja norma utilizada é a do PE, conforme o exemplo em (3):

(3)

Ele comprou estas revistas (p. 216).

O mesmo manual aborda o aspecto da coesão, definindo-a como a ligação dos elementos textuais através de uma série de mecanismos, fundamentalmente linguísticos (MAGALHÃES; COSTA; SILVA, 2005, p. 237).

Recorrendo a Prada (2006 [Web]) o manual de apoio ao ensino da língua portuguesa para a $11^{\text {a }}$ Classe apresenta a seguinte definição:

Entende-se por coesão um conjunto de processos que, recorrendo a determinados grupos de vocábulos, ou classes de palavras, permite fazer um texto a partir de um "puzzle" de frases soltas (ou mesmo uma frase a partir de palavras soltas).

Segundo o manual, os mecanismos que garantem a coesão frásica são a ordem das palavras e a concordância em gênero e número. Depreende-se, portanto, que a não existência de concordância no Nome, configura inexistência de coesão, portanto um erro. Este tratamento exclui completamente a possibilidade de considerar a variante da língua, produto do contato entre o Português e as línguas bantu.

Ao apontar as características do português falado por estudantes universitários na cidade do Cuito, Pinto (2021) constatou a existência de desvios de concordância em relação ao $\mathrm{PE}$, no qual os valores de gênero e número do nome determinam a concordância com os elementos do mesmo SN. Na mesma senda, Pessela (2020) ao analisar aspetos da concordância de número no SN no português falado por alunos bilingues da $6^{\mathrm{a}}$ Classe, da $11^{\mathrm{a}}$ Classe, do $1^{\circ}$ e $2^{\circ}$ anos da universidade constatou a existência de estratégia de marcação mista da concordância de número em SNs complexos.

Este fenômeno de marcação variável da concordância de número, com a tendência de marcar o plural apenas no elemento mais à esquerda do SN, não é um caso isolado de falantes 
desta região de Angola. Há estudos de outras regiões de Angola que aponta para a mesma tendência, tais como os estudos de Inverno (2009) que analisa o português falado na LundaNorte, Adriano (2014), que analisa o português falado na Huíla, Hagemeijer (2009), que analisa o português falado no Norte e Sul de Angola, onde o Português convive com o Kimbundu e o Umbundu, respetivamente. Todos estes autores evidenciam a existência não só da variação nos mecanismos de concordância entre os elementos $\mathrm{SN}$, como também a tendência generalizada de marcação do plural nos elementos mais à esquerda do SN. Este fato, ainda na ótica dos autores referenciados deve-se ao fato de a concordância de número nas línguas bantu faladas em Angola, ser marcada por prefixação (cf. ex. 1d). Face a isto, dado ao fato de o Português ser aprendido como L2 para muitos falantes angolanos, decidimos analisar o tratamento dado a esta tendência gramatical nos manuais e programas de ensino do Português.

O manual da $11^{\mathrm{a}}$ Classe aborda o assunto dos registros de língua, ligado a vários fatores, destacando, todavia, a língua padrão, também conhecida como norma ou registro corrente, preservada pela escola, pelos meios de comunicação social e pela literatura. O manual que estamos a citar defende: "A norma deve, pois, ser adquirida durante a vida escolar, já que o seu domínio é essencial como forma de ascensão social e profissional" (MAGALHÃES; COSTA; SILVA, 2005, p. 157). E mais afirma: "Em relação à norma (ou registro corrente), cada um dos outros registros constitui um desvio, uma variação".

Os programas do $1^{\circ}$ e $2^{\circ}$ ano do ensino superior de formação de professores, abordam aspectos sobre as variedades do português, mas quase nada abordam sobre a variação da concordância, além disso coincidem com a concepção de que a variação é um desvio em relação à norma padrão.

Diante realidade assistimos uma disparidade entre as práticas linguísticas cotidianas e as práticas linguísticas em sala de aulas. Apesar de insistir-se num ensino português que privilegia a norma do Português Europeu PE, dever-se-ia adotar um ensino mais próximo das características linguísticas constatadas através dos dados apresentados. Os desvios em relação a norma do PE mostram que são uma realidade visível a todos os níveis, pois constatou-se que estes desvios estão presentes tanto em falantes de baixo nível como nos de alto nível de escolaridade.

$\mathrm{Na}$ opinião dos autores deste trabalho, a persistência no ensino do Português baseado na norma do PE, sem considerar a realidade linguística de Angola, eterniza os erros de concordância. Para o efeito, no sentido de contrapor esta realidade, dever-se-ia normatizar o Português de Angola (PA) capaz de prever e abarcar todas as características adstritas à essa 
variante, entre as quais a concordância de número, já constatada por vários autores (PINTO, 2021; ADRIANO, 2015; NZAU, 2011). Na mesma senda, atendendo ao perfil linguístico dos alunos angolanos, consideramos urgente a inserção nos programas, manuais e demais meios de ensino de aspectos típicos do PA, de modo a diminuir o fosso entre as práticas linguísticas cotidianas e a norma ensina no meio acadêmico.

\section{Considerações finais}

Depois de apresentarmos alguns fundamentos sobre a variação da concordância de número no SN no Português de Angola, com base nos dados analisados concluímos.

Os falantes do português de Angola apresentam uma marcação mista da concordância de número independentemente do nível de escolaridade.

As divergências no mecanismo de concordância em relação ao $\mathrm{PE}$, derivam principalmente de aspectos que resultantes do contato linguístico entre o Português e as línguas bantu faladas em Angola.

No processo de ensino e aprendizagem do Português não se tem considerado as características típicas do PA, dificultando, assim, a apropriação e a construção de uma gramática que reflita a realidade Angolana.

\section{REFERÊNCIAS}

ADRIANO, P. S. A crise Normativa do Português em Angola: cliticalização e regência verbal: que atitude normativa para o professor e o revisor? Luanda: Mayamba, 2015.

GONC,̧LVES, P. O Português em África. In: RAPOSO, E.P. et al. (org.). Gramática do Português. Lisboa: Fundação Calouste Gulbenkian, 2013. p. 157-178.

GREENBERG, J.H. Universals of language. Cambridge: The MIT Press, 1996.

HAGEMEIJER, T.O Português em contato em África. In: MARTINS, A.M.; CARRILLO, E. (org.). Manual de Linguística Portuguesa. De Gruyter, 2009. p. 50-53.

INVERNO, L. Contact-induced restructuring of Portuguese morphosyntax in interior Angola: Evidence from Dundo (Lunda Norte). 2009. 476 f. Dissertação (Doutorado) Doutoramento em Letras: Línguas e Literaturas Modernas, Universidade de Coimbra (UC), Coimbra, 2009.

KATAMBA, F. Bantu nominal morphology. In: DEREK, N.; GERARD, Ph (org.) The Bantu Languages Routledge Languages Family. Series 4. London: Taylor and Francis Routledge, 2003. p. 101-103. 
MAGALHÃES, O; COSTA, F.; SILVA, L. Língua portuguesa $1^{\text {a }}$ classe. Porto: Porto Editora, 2005.

MAGALHÃES, O; COSTA, F.; SILVA, L. Língua portuguesa 11ª classe. Porto: Porto Editora, 2008.

PESSELA, J. D. Sobre a Concordância de Número no SN no PA-Variante do Português de Cuito-Bié. 2020. Dissertação (Mestrado em Linguística) - Faculdade de Letras, Universidade do Porto, Porto, 2020.

PINTO. H. K. C. S.O.S Umbundu: de L1 a L 0. Abordagem da Situação Sociolinguística. 1. ed. Chișinău: Novas Edições Académicas, 2021. 108 p. ISBN-13: 978-620-3-46847-2.

PRADA, E. Mecanismos de coesão linguística. Ciberdúvidas da Língua Portuguesa, 2006. Disponível em: https://ciberduvidas.iscte-iul.pt/consultorio/perguntas/mecanismos-de-coesaolinguuistica/17021. Acesso em: 10 jul. 2021.

ZAU, D. G. D. A Língua Portuguesa em Angola: Um contributo para o estudo da sua nacionalizacãa. 2011. Tese (d outorado em Linguística) - Universidade da Beira Interior (UBI), Covilhã, Portugal, 2011.

ZAU, D. G. D. et al. 2013. Em torno da consagração de uma variante angolana do português: subsídios para uma reflexão. Limite, Cáceres (Espanha), n. 7, p. 159-180, 2013.

\section{Como referenciar este artigo}

PINTO, H. K. C.; PESSELA, J. D. Reflexões sobre a concordância de número em sintagmas nominais (SNs) complexos no português de angola (PA). Rev. EntreLínguas, Araraquara, v 7, $\mathrm{n}$ esp. 6, e021137, dez. 2021. e-ISSN: 2447-529. DOI: https://doi.org/10.29051/el.v7iesp.6.15373

Submetido em: 14/08/2021

Revisões requeridas em: 28/09/2021

Aprovado em: 12/11/2021

Publicado em: 28/12/2021 